\title{
TRANSPORT OF Zn(II), Fe(II), Fe(III) ACROSS polymer inclusion membranes (pim) and Flat sheet supported liquid membranes (s/m) containing phosphonium ionic liquids as metal ion carriers
}

\author{
Monika BaczyŃska, Magdalena Regel-Rosocka, Maria Teresa Coll, Agustin \\ Fortuny, Ana Maria Sastre \& Maciej WiŚniewski
}

To cite this article: Monika BaczyŃska, Magdalena Regel-Rosocka, Maria Teresa Coll, Agustin Fortuny, Ana Maria Sastre \& Maciej WiŚniewski (2016): TRANSPORT OF Zn(II), Fe(II), Fe(III) ACROSS polymer inclusion membranes (pim) and Flat sheet supported liquid membranes $(\mathrm{s} / \mathrm{m})$ containing phosphonium ionic liquids as metal ion carriers, Separation Science and Technology, DOI: $10.1080 / 01496395.2016 .1174265$

To link to this article: http://dx.doi.org/10.1080/01496395.2016.1174265

Accepted author version posted online: 18 Apr 2016.

Submit your article to this journal ¿

View related articles $\longleftarrow$

View Crossmark data $₫$ 


\section{TRANSPORT OF Zn(II), Fe(II), Fe(III) ACROSS polymer inclusion membranes (pim) and Flat sheet supported liquid membranes (slm) containing phosphonium ionic liquids as metal ion carriers}

\section{Shorten title: Transport of $\mathrm{Zn}(\mathrm{II}), \mathrm{Fe}(\mathrm{II}), \mathrm{Fe}(\mathrm{III})$ across PIMs and SLMs}

monika baczyŃska ${ }^{1}$, magdalena regel-rosocka ${ }^{1 *}$, maria teresa coll ${ }^{2}$, agustin fortuny ${ }^{2}$, ana maria sastre $^{2}$, maciej wiŚniewski ${ }^{1}$

1 Poznan University of Technology, Institute of Chemical Technology and Engineering, Berdychowo St. 4, 60-965 Poznan, Poland

2 Universitat Politècnica de Catalunya, Department of Chemical Engineering, Av. Victor Balaguer 1, 08800 Vilanova i la Geltru, Spain

*email: magdalena.regel-rosocka@put.poznan.pl

Abstract

In this work transport of $\mathrm{Zn}(\mathrm{II}), \mathrm{Fe}(\mathrm{II})$ and $\mathrm{Fe}(\mathrm{III})$ ions from chloride aqueous solutions across polymer inclusion membranes (PIMs) and supported liquid membranes (SLMs) containing one of three phosphonium ionic liquids: trihexyl(tetradecyl)phosphonium chloride (Cyphos IL 101), trihexyl(tetradecyl)phosphonium bis(2,4,4-trimethylpentyl)phosphinate (Cyphos IL 104) and tributyl(tetradecyl)phosphonium chloride (Cyphos IL 167) as ion carrier was reported. The results show that $\mathrm{Zn}(\mathrm{II})$ and $\mathrm{Fe}(\mathrm{III})$ are effectively transported through PIMs and SLMs, while $\mathrm{Fe}$ (II) transport is not effective. The highest values of initial flux and permeability coefficient of Zn(II) were noticed for SLM containing Cyphos IL 167. Cyphos IL 101-containing SLM is more stable than PIM. 
Keywords: Supported liquid membranes, Polymer inclusion membranes, $\mathrm{Zn}(I I), \mathrm{Fe}(I I), \mathrm{Fe}(I I I)$ transport, Phosphonium ionic liquids

\section{introduction}

Lastly, remarkable progress has been made concerning the separation and removal of metal ions through liquid membranes. Many applications of supported liquid membranes and polymer inclusion membranes as an alternative method to traditional liquid-liquid extraction (SX) were proposed in scientific literature. The advantages of these membranes over SX include elimination in amount of volatile solvents from separation systems and reduction of intermediate steps (1). Also, such drawbacks of liquid-liquid extraction as loading limits of the organic phase and losses of metal ions in the interfacial phases are eliminated.

Generally, liquid membranes are classified as bulk liquid membranes (BLMs), emulsion liquid membranes (ELMs) and supported liquid membranes (SLMs). The main drawback of BLMs lies in their small surface area and slow mass transfer rates, whereas emulsion stability is the main problem of ELM operation (1-4).

SLMs are formed as flat sheets, tubes, spiral-wound or hollow fiber. A common problem for SLMs is the loss of membrane phase to both aqueous phases and subsequently short lifetime. For this reason these membranes are not widely used on industrial scale nowadays (3). However, different configurations of the SLM give the opportunity to develop large surface area of the membrane and, thus, enhance the efficiency of solute mass transport. 
To overcome the drawback of instability of impregnated SLMs, polymer inclusion membranes (PIMs) have been developed. The main difference between these two types of liquid membranes lies in the way of carrier immobilization: in SLM the organic phase containing carrier impregnates pores of a solid support and is kept there by capillary forces, while in PIM the carrier itself is built into the structure of the membrane which is composed of a polymer support material (mainly cellulose triacetate (CTA) or poly(vinyl chloride) (PVC)), carrier (extractant) and a plasticizer or modifier. Good stability of PIMs (5), limited loss of carriers (6), high selectivity and transport efficiency (7) compared to other types of liquid membranes are the main reasons for the recent interest in the metal ion transport through polymer inclusion membranes $(1,2,4,8)$.

Some authors compared transport of $\mathrm{Zn}(\mathrm{II}), \mathrm{Cu}(\mathrm{II}), \mathrm{Co}(\mathrm{II}), \mathrm{Ni}(\mathrm{II}), \mathrm{Pt}(\mathrm{IV})$ across PIMs and flat sheet SLMs (9-13). Different carriers were included in PIMs or impregnated into SLMs, e.g. calix[4]resorcinarene derivatives (9), 1-decyl-4-methylimidazole (10), quaternary ammonium (e.g. methyltrioctylammonium chloride, Aliquat 336) (11, 13), lauric acid (12), Lasalocid sodium salt (13), bis(2-ethylhexyl)phosphoric acid (D2EHPA) (14, 15), 7-(4-ethyl-1-methyloctyl)-8hydroxyquinoline (Kelex 100) (16), trialkylphosphine oxide (Cyanex 923) (17). Recently also phosphonium ionic liquids have been extensively investigated as carriers of $\mathrm{B}(\mathrm{III})$ (18), $\mathrm{Cu}(\mathrm{II})$ (11), $\mathrm{Zn}(\mathrm{II}), \mathrm{Fe}(\mathrm{II}), \mathrm{Fe}(\mathrm{III})$ (19-23), $\mathrm{Cd}(\mathrm{II}), \mathrm{Co}(\mathrm{II}), \mathrm{Ni}(\mathrm{II})$ (24). Quaternary phosphonium ionic liquids, i.e. trihexyl(tetradecyl)phosphonium chloride (Cyphos IL 101), trihexyl(tetradecyl)phosphonium bis(2,4,4-trimethylpentyl)phosphinate (Cyphos IL 104) and tributyl(tetradecyl)phosphonium chloride (Cyphos IL 167) were also tested as metal ion carriers across SLMs $(11,18,25)$. Regel-Rosocka et al. (23) described removal of $\mathrm{Zn}(\mathrm{II}), \mathrm{Fe}(\mathrm{II})$ and 
Fe(III) from chloride aqueous solutions across PIMs containing Cyphos IL 101 and Cyphos IL 104 as metal ion carriers. The obtained results showed that Cyphos IL 101 is a more effective carrier for $\mathrm{Fe}(\mathrm{III})$ than for $\mathrm{Zn}(\mathrm{II})$ ions (23).

The obtained values of permeability coefficient showed that flat sheet SLM better transferred $\mathrm{Zn}$ (II) from feed to receiving phase than PIM did (9). The differences between the rate and efficiency of $\mathrm{Zn}(\mathrm{II})$ transport through PIMs and SLMs were attributed to the differences in structure of the membranes and distinct forces binding carrier with the membrane support. Consequently, different mechanisms of solute transport across the membrane are responsible for the effectiveness of the separation. On the contrary, Ulewicz and Radzymińska-Lenarcik (10) found that initial flux of $\mathrm{Zn}(\mathrm{II})$ across PIMs containing imidazole derivative is higher than across SLM. However, after taking into account different morphology (porosity, tortuosity) of these two types of liquid membranes (i.e. normalizing the fluxes), and recalculation of the values of $\mathrm{Zn}$ (II) initial flux, the transport through PIMs appeared to be worse than the transport across SLMs. Also, $\mathrm{Cu}(\mathrm{II})$ transport with lauric acid as a carrier across SLM was reported to be higher than across PIM (12). Furthermore, Fontas et al. (13) reported that (after normalizing the fluxes) efficiencies of Pt(IV) and Cd(II) transport across SLMs and PIMs were comparable.

Though lower mass fluxes are reported in the most cases, all authors emphasized that PIMs were more stable than SLMs and, hence, were preferred for some applications. Many researchers have studied the stability of PIMs and reusability by performing repeated transport experiments with the same membrane. Generally, the stability of PIMs was quite good with flux and permeability 
values changing only slightly in the first several cycles and also no structural weakening of the membrane was reported $(10,14,15,26-28)$.

The aim of the present work is to compare the transport of $\mathrm{Zn}(\mathrm{II}), \mathrm{Fe}(\mathrm{II})$ and $\mathrm{Fe}(\mathrm{III})$ ions through polymer inclusion membranes and flat sheet supported liquid membranes containing one of three phosphonium ionic liquids (Cyphos IL 101, Cyphos IL 104 and Cyphos IL 167) as metal ion carriers. Though spent pickling solutions contain $\mathrm{Zn}(\mathrm{II})$ and mainly $\mathrm{Fe}(\mathrm{II})$ it was shown that $\mathrm{Fe}(\mathrm{II})$ can be partly oxidized to Fe(III) (29). This is the reason for studies both on $\mathrm{Fe}(\mathrm{II})$ and $\mathrm{Fe}(\mathrm{III})$ transport across liquid membranes and on separation of $\mathrm{Zn}(\mathrm{II})$ from Fe ions. Also, stability of PIM and SLM is compared for Cyphos IL 101 as a metal ion carrier.

\section{experimental}

\section{Reagents and solutions}

The inorganic chemicals, i.e. $\mathrm{Zn}(\mathrm{II}), \mathrm{Fe}(\mathrm{II})$ and $\mathrm{Fe}(\mathrm{III})$ chlorides were of analytical grade. The organic reagents, i.e. cellulose triacetate (CTA), $o$-nitrophenyloctyl ether (NPOE), dichloromethane, decanol, kerosene were also of analytical grade and were purchased from Fluka and used without further purification. Phosphonium ionic liquids, trihexyl(tetradecyl)phosphonium chloride (Cyphos IL 101), tributyl(tetradecyl)phosphonium

chloride (Cyphos IL 167) and trihexyl(tetradecyl)phosphonium bis(2,4,4trimethylpentyl)phosphinate (Cyphos IL 104) supplied by Cytec Industries Inc. (USA) were applied as carriers for metal ions in PIMs and SLMs (Fig. 1). The aqueous feed phase contained 
$1.5 \cdot 10^{-3} \mathrm{M} \mathrm{Zn}$ (II) $\left(0.1 \mathrm{~g} / \mathrm{dm}^{3}\right)$ and $1.8 \cdot 10^{-3} \mathrm{M} \mathrm{Fe}$ ions $\left(0.1 \mathrm{~g} / \mathrm{dm}^{3}\right), 0.58 \mathrm{M} \mathrm{HCl}, 5 \mathrm{M} \mathrm{Cl}^{-}$(constant chloride content was adjusted with $\mathrm{NaCl}$ ). $1 \mathrm{M} \mathrm{H}_{2} \mathrm{SO}_{4}$ was used as a receiving phase.

Fig. 1. Structures of the phosphonium ionic liquids used as PIM carriers.

The carriers differed with the structure of cations or anions that might affect the reaction of extraction of various metal species and, thus, could influence the efficiency of transport of metal ions across the liquid membranes.

\section{Preparation of membranes}

\section{Polymer inclusion membranes}

Solution of cellulose triacetate as the polymer matrix, plasticizer (NPOE), Cyphos IL 101, Cyphos IL 104 or Cyphos IL 167 as ion carriers in dichloromethane (solvent) was prepared. A specific portion of the three-component organic solution was poured into a Petri dish. After slow evaporation of organic solvent (at least for $24 \mathrm{~h}$ ) the obtained polymer inclusion membrane was carefully peeled off from the glass dish by immersion in a cold water. The composition of PIMs applied for the studies was the following: 55\% CTA, 40\% IL and 5\% NPOE. It is assumed that the composition of the membrane is equivalent to the composition of the casting solution.

Supported liquid membranes

A flat sheet PVDF (polyvinylidene fluoride, Durapore HVHP04700) was used as polymeric support for transport of $\mathrm{Zn}(\mathrm{II}), \mathrm{Fe}(\mathrm{II})$ and $\mathrm{Fe}(\mathrm{III})$. The organic liquid membrane phase was 
prepared by dissolving the required volume of 0.1 M Cyphos IL 101, Cyphos IL 104 and Cyphos IL 167 in 10\% decanol/kerosene to obtain carrier solutions. The supported liquid membranes were prepared at room temperature by impregnating the porous support with the carrier solution overnight, then leaving them to drip for $10 \mathrm{~s}$ before being placed in an apparatus.

Characteristic parameters of the membranes used are given in Table 1.

Table 1. Characteristic parameters of PIMs and SLMs applied for metal ion transport.

\section{Transport studies}

To transport $\mathrm{Zn}(\mathrm{II}), \mathrm{Fe}(\mathrm{II})$ and Fe(III) across PIMs, a sandwich type membrane module was used, to which feed and receiving phase were pumped with a peristaltic pump from tanks containing both phases. The volumes of aqueous solutions were equal to $200 \mathrm{~cm}^{3}$. The effective membrane area was $15.9 \mathrm{~cm}^{2}$. Fig. 2 illustrates the schematic diagram of the metal ion transport experiments across PIMs (20-23).

The SLM transport experiments were carried out in the flat sheet (FSSLM) apparatus presented in Fig. 3. Batch experiments were carried out in two cylindrical cells containing $210 \mathrm{~cm}^{3}$ of each the feed and receiving solution. The effective area of SLM was equal to $11.4 \mathrm{~cm}^{2}$. Both phases were mechanically stirred. Samples from the feed and receiving phases were withdrawn at regular time intervals, and metal ion concentration was analyzed by atomic absorption spectroscopy (AAS, Hitachi Z-8200 or 4100 MP-AES, Agilent Technologies, AA 240FS, Varian) at 213.8 and $248.3 \mathrm{~nm}$ (for zinc and iron, respectively) in the air-acetylene flame. 
Fig. 2. Schematic diagram of PIM system (1 - feed phase container, 2 - receiving phase container, 3 - peristaltic pump, 4 - membrane module - sandwich type).

Fig. 3. Scheme of SLM system.

The kinetics of PIM and SLM transport can be described by an equation analogous to the first order reaction in relation to metal ion concentration:

$\ln \frac{c}{c_{0}}=-k t$

where $c_{0}(\mathrm{M})$ and $c(\mathrm{M})$ is the concentration of metal ions in the feed phase at initial time and selected time, $k$ is the rate constant $(1 / \mathrm{s}), t$ is the time of transport (s). Values of the rate constant (k) are estimated from linear dependence of $\ln \left(c / c_{0}\right)$ versus time.

Transport abilities of PIMs and SLMs are characterized by initial flux of metal ions $\left(J_{o}, \mathrm{~mol} / \mathrm{s} \cdot \mathrm{m}^{2}\right)$ :

$J_{0}=\frac{V}{A} \cdot k \cdot c_{0}$

where $V$ is the volume of the aqueous phase $\left(2 \cdot 10^{-4} \mathrm{~m}^{3}, 2.1 \cdot 10^{-4} \mathrm{~m}^{3}\right.$, respectively for PIMs and SLMs), $A$ is an effective membrane area (Table 1). Permeability coefficient can be calculated at feed and receiving phase side $\left(P_{F}, P_{R}, \mathrm{~m} / \mathrm{s}\right.$, respectively) from the slope of the graph assuming the following dependences (16):

$\ln \left(\frac{c}{c_{0}}\right)=-P_{F} \cdot \frac{V}{A} \cdot t$ 
$\ln \left(\frac{c_{0}-c_{R}}{c_{0}}\right)=-P_{R} \cdot \frac{V}{A} \cdot t$

Efficiency of metal ions extraction to the membrane (E, \%) and recovery factor (RF, \%) of metal ions (calculated after 48 or $72 \mathrm{~h}$ of the process, for $\mathrm{Zn}(\mathrm{II})$ and Fe ions, respectively) and are defined by eqs. 5 and 6.

$E=\frac{c_{0}-c}{c_{0}} \cdot 100 \%$

$R F=\frac{c_{R}}{c_{0}} \cdot 100 \%$

$c_{R}$ is the concentration of metal ions in the receiving solution at selected time.

\section{results and discussion}

\section{$\mathrm{Zn}(\mathrm{II}), \mathrm{Fe}(\mathrm{II})$ and $\mathrm{Fe}(\mathrm{III})$ presence in chloride solutions}

Chloride solutions containing $\mathrm{Zn}(\mathrm{II}), \mathrm{Fe}(\mathrm{II})$ and $\mathrm{Fe}(\mathrm{III})$ were chosen for studies with liquid membranes because removal and separation of these metal ions is an important issue to be solved for hot-dip galvanizing industry (30) due to high concentratins reaching even up to 120 $\mathrm{g} / \mathrm{dm}^{3} \mathrm{Zn}(\mathrm{II}), 100 \mathrm{~g} / \mathrm{dm}^{3} \mathrm{Fe}$ ions (mainly Fe(II)) and $3 \mathrm{M} \mathrm{HCl}$. Fe(III) can be present in these solutions as a consequence of oxidation of Fe(II) (29). Detailed information on composition of spent pickling solutions and methods of their regeneration was presented in some previous papers $(30,31)$. 
Recently, not only liquid-liquid extraction has been proposed to recover $\mathrm{Zn}$ (II) from spent pickling baths $(23,32,33)$ but also emulsion pertraction technology (34), membrane-based solvent extraction $(34,35)$ or its combination with electrowinning $(31)$ or anion exchange $(36)$.

Generally, Fe(III) and $\mathrm{Zn}$ (II) form stable neutral and anionic chlorocomplexes in the presence of hydrochloric acid and high content of chloride anions, while Fe(II) anionic chlorocomplexes are not stable in the aqueous phases, and $\mathrm{Fe}(\mathrm{II})$ exists in aqueous chloride media mainly as $\mathrm{Fe}^{2+}$ or $\mathrm{FeCl}^{+}(29)$.

Phosphonium ILs used as ion carriers are able to react with anionic or neutral chlorocomplexes of $\mathrm{Zn}$ (II) or $\mathrm{Fe}$ (III) depending on the chloride and hydrochloric acid concentrations in accordance with the following reactions (32):

$$
\begin{aligned}
& \mathrm{ZnCl}_{4(\text { aq })}^{2-}+2 \overline{\mathrm{R}_{3} \mathrm{R}^{\prime} \mathrm{PCl}} \Leftrightarrow \overline{\left(\mathrm{R}_{3} \mathrm{R}^{\prime} \mathrm{P}\right)_{2} \mathrm{ZnCl}_{4}}+2 \mathrm{Cl}_{\mathrm{aq}}^{-} \\
& \mathrm{ZnCl}_{4(\text { (aq) }}^{2-}+2 \mathrm{H}_{\text {(aq) }}^{+}+2 \overline{\mathrm{R}_{3} \mathrm{R}^{\prime} \mathrm{PA}} \Leftrightarrow \widehat{\left(\mathrm{R}_{3} \mathrm{R}^{\prime} \mathrm{P}\right)_{2} \mathrm{ZnCl}_{4}}+2 \overline{\mathrm{HA}} \\
& \mathrm{FeCl}_{3(\text { (aq })}+\overline{\mathrm{R}_{3} \mathrm{R}^{\prime} \mathrm{PCl}} \Leftrightarrow \overline{\left(\mathrm{R}_{3} \mathrm{R}^{\prime} \mathrm{P}\right) \mathrm{FeCl}_{4}}
\end{aligned}
$$

By contrast extraction of $\mathrm{Fe}$ (II) could theoretically follow the reaction:

$$
\mathrm{Fe}_{(\mathrm{aq})}^{2+}+2 \mathrm{Cl}_{(\mathrm{aq})}^{-}+\overline{\mathrm{R}_{3} \mathrm{R}^{\prime} \mathrm{PCl}} \Leftrightarrow \overline{\left(\mathrm{R}_{3} \mathrm{R}^{\prime} \mathrm{P}\right) \mathrm{FeCl}_{3}}
$$

or Cyphos IL 104 can bind also iron cations to bis(2,4,4-trimethylpentyl)phosphinate anion (denoted as $\mathrm{A}$ in eq. 11) originating from acidic extractant bis(2,4,4-trimethylpentyl)phosphinic acid (Cyanex 272) according to the reaction: 


$$
\mathrm{Fe}_{(\mathrm{aq})}^{2+}+2 \mathrm{Cl}_{(\mathrm{aq})}^{-}+2 \overline{\mathrm{R}_{3} \mathrm{R}^{\prime} \mathrm{PA}} \Leftrightarrow 2 \overline{\left(\mathrm{R}_{3} \mathrm{R}^{\prime} \mathrm{P}\right) \mathrm{Cl}}+\overline{\mathrm{FeA}_{2}}
$$

However, it was shown that Cyanex 272, as an acidic extractant, did not efficiently extract metal ions from feeds at low $\mathrm{pH}$ (below 1) (37).

\section{$\mathrm{Zn}(\mathrm{II}), \mathrm{Fe}(\mathrm{II})$ and $\mathrm{Fe}(\mathrm{III})$ transport through SLMs}

Flat sheet SLMs impregnated with three various phosphonium ILs were used to investigate transport of $\mathrm{Zn}(\mathrm{II}), \mathrm{Fe}(\mathrm{II})$ and $\mathrm{Fe}(\mathrm{III})$. Generally, as a consequence of metal ion transport across a membrane, the content of metal ions in the feed phase decreases while it increases in the receiving phase. Fig. 4 shows the exemplary changes in $\mathrm{Zn}(\mathrm{II}), \mathrm{Fe}(\mathrm{II})$ and $\mathrm{Fe}(\mathrm{III})$ concentration over time during transport through SLMs containing Cyphos IL 101 as a carrier. Concentration profiles across SLMs with Cyphos IL 104 and Cyphos IL 167 are shown in Supplementary Data (Fig. 8).

Fig. 4. Changes in concentration of (•) $\mathrm{Zn}(\mathrm{II}),(\bullet) \mathrm{Fe}(\mathrm{II}),(\boldsymbol{\Delta}) \mathrm{Fe}(\mathrm{III})$ ions over time in the feed and receiving phase through SLMs with Cyphos IL 101 as a carrier.

As shown in Figs. 4 and 8 (Supplementary Data) concentrations of $\mathrm{Zn}(\mathrm{II})$ and $\mathrm{Fe}(\mathrm{III})$ ions in the feed phase decrease faster and finally reach lower values compared to Fe(II), for Cyphos IL 101 and 167 carriers. After three hours of the process more than $25 \%$ of the initial amount of $\mathrm{Fe}(\mathrm{III})$ is transported from the feed phase to the receiving phase across the SLM containing Cyphos IL 101 and IL 167 (Figs. 4 and 8). Also, the transport of Zn(II) across the membranes impregnated 
with Cyphos IL 101 and IL 167 is effective. On the contrary, the transport of $\mathrm{Fe}(\mathrm{II})$ is not effective across the SLMs containing one of these three carriers.

\section{$\mathrm{Zn}(\mathrm{II}), \mathrm{Fe}(\mathrm{II})$ and $\mathrm{Fe}(\mathrm{III})$ transport through PIMs}

The transport of $\mathrm{Zn}$ (II), $\mathrm{Fe}$ (II) and $\mathrm{Fe}(\mathrm{III})$ was also carried out through PIMs containing 55\% CTA, 40\% IL, 5\% NPOE to compare it with transport across SLMs. Concentration profiles of metal ions are presented in Figs. 5 and 9 (Supplementary Data).

Fig. 5. Changes in concentration of $(\boldsymbol{\bullet}) \mathrm{Zn}(\mathrm{II}),(\bullet) \mathrm{Fe}(\mathrm{II}),(\boldsymbol{\Delta}) \mathrm{Fe}(\mathrm{III})$ ions over time in the feed and receiving phase through PIMs with Cyphos IL 101 as a carrier.

A similar trend as for SLMs is noted also for transport across PIMs: concentrations of $\mathrm{Zn}(\mathrm{II})$ and Fe(III) in the feed phase decrease faster than Fe(II) content (Figs. 5 a and 9 c, e). Generally speaking, the transport of Fe(II) across the both types of liquid membranes, i.e. SLM and PIM, is not effective. After $72 \mathrm{~h}$ less than 10 and $40 \%$ of initial amount of Fe(II) (respectively for SLMs and PIMs) is extracted from the feed phase. Small amount of iron ions detected in the receiving phases during $\mathrm{Fe}(\mathrm{II})$ transport may probably result from oxidation of $\mathrm{Fe}$ (II) to $\mathrm{Fe}$ (III).

\section{Comparison of transport of metal ions across PIMs and SLMs}

These two types of liquid membranes were studied to learn about their individual performance towards transport of $\mathrm{Zn}(\mathrm{II}), \mathrm{Fe}(\mathrm{II})$ and $\mathrm{Fe}(\mathrm{III})$ with phosphonium ionic liquids as ion carriers. On the basis of the concentration changes presented above some parameters characterizing transport of metal ions were calculated (eqs. 2-6). 
The differences in the membrane thicknesses affect the flux value, so the initial fluxes for PIMs were normalized $\left(J_{N}\right)$ according to the following equation (38):

$$
J_{N}=J_{0, P I M} \cdot \frac{d_{P I M}}{d_{S L M}}
$$

where $d_{S L M}$ equals $125 \mu \mathrm{m}$ and is the supported liquid membrane thickness, $d_{P I M}$ corresponds to the thickness of the membrane whose flux is normalized.

The obtained results showed that the transport of metal ions to the receiving phase across both SLMs and PIMs containing Cyphos IL 101 and Cyphos IL 167 was faster than transport across the membrane containing Cyphos IL 104 (Figs. 4, 5, 8 and 9). These observations were also confirmed by the values of initial fluxes and permeability coefficients of $\mathrm{Zn}(\mathrm{II}), \mathrm{Fe}(\mathrm{II})$ and Fe(III) for SLMs and PIMs calculated according to eqs 2-4 and presented in Table 2. For example, very low initial transport of $\mathrm{Zn}(\mathrm{II}), \mathrm{Fe}(\mathrm{II})$ and $\mathrm{Fe}(\mathrm{III})$ was noted across SLM containing Cyphos IL 104 (Table 2). It seems that in SLMs the metal ion-Cyphos IL 101 and Cyphos IL 167 complexes may be easier transported, thus, leading to higher values of $J_{N}$ and $P_{F}$ than for SLM containing Cyphos IL 104. The maximum values of Zn(II) transport across SLMs and PIMs were noted for the membrane containing Cyphos IL 167, which consisted of small chloride anion and cation substituted with shorter alkyl chains than Cyphos IL 101 and Cyphos IL 104 (Fig. 1). It can be explained by the fact that the membranes containing smaller carriers (Cyphos IL 167 or Cyphos IL 101) have higher mobility than Cyphos IL 104 (containing bulky anion) to transport metal ions from the feed to the receiving phase. Thus, it is visible that the structure of the carriers used affects the efficiency of transport of metal ions across the liquid membranes. 
The transport parameters should be interpreted also in the light of metal chlorocomplexes formed in the solution and their reactions with the carriers. $\mathrm{Zn}$ (II) and Fe(III) anionic chlorocomplexes act with phosphonium ILs according to anion-exchange reactions (eq. 7 and 8), while transport of neutral $\mathrm{Fe}$ (III) chlorocomplex and $\mathrm{Fe}$ (II) cations can be explained by addition reactions (eq. 9 and 10). However, a significant increase in Cyphos IL 104 extraction efficiency of $\mathrm{Fe}(\mathrm{II})$ (particularly in PIMs) compared with Cyphos IL 101 and 167 indicates that reaction with anion of Cyphos IL 104 according to eq. 11 is justified. Similar reactions of extraction were proposed for $\mathrm{Cd}^{2+}, \mathrm{CdCl}^{+}$and $\mathrm{CdCl}_{3}{ }^{-}$transport across CTA-based PIM with Cyphos IL 104 by Pospiech (24).

The differences in the normalized fluxes that are one order smaller for PIMs than these for SLMs reflect influence of the way of immobilization of the carrier in the membrane. Smaller values of metal ion fluxes can be explained by restricted mobility of carriers that is assumed to be responsible for solute transport in the bulk PIM (1). Carriers are built into the structure of a polymer matrix in PIMs, while in SLMs the membrane pores are impregnated with a carrier solution which make the carrier move easier in SLMs than in PIMs. This phenomena was indicated also by other authors $(9,10,12,39)$. Ugur et al. (9) compared $\mathrm{Zn}$ (II) transport across SLM and PIM containing calix[4]resorcinarene derivative indicating that $\mathrm{Zn}$ (II) fluxes across SLMs were slightly greater that across PIMs, and attributed it to the various structures of these two types of liquid membranes. The same tendency was noted by Ulewicz and RadzyminskaLenarcik (10) who obtained lower values of $\mathrm{Zn}(\mathrm{II})$ initial flux across PIM with 1-decyl-4methylimidazole as ion carrier than across SLM. Paugam et al. (12) found diffusion coefficient in CTA-based PIM containing lauric acid as a carrier and tris(2-ethylhexyl) phosphate as a 
plasticizer to be 22 times lower than in the corresponding SLM. Authors suggested that the reason for such a difference in diffusivity of $\mathrm{Cu}(\mathrm{II})$ lies in chemical interactions of the diffusing species with the CTA polymer or physical resistance due to the mesh size of the CTA membrane. Higher permeability of SLM containing Kelex 100 as a carrier for $\mathrm{Pb}(\mathrm{II})$ and $\mathrm{Cd}(\mathrm{II})$, than CTAbased PIM with the same carrier, was explained by Aguilar et al. (39) by lower total transport resistance in SLMs.

Table 2. The comparison of parameters characterizing transport of $\mathrm{Zn}$ (II), $\mathrm{Fe}$ (II) and $\mathrm{Fe}$ (III) through SLMs and PIMs.

Differences in the results of permeability coefficient at the feed and receiving phase $\left(P_{F}\right.$ and $\left.P_{R}\right)$ indicate retention of the metal ion within the membrane, particularly in PIMs. Only for transport of small amounts of Fe(II) across SLMs no accumulation of the solute in the membrane is observed. The accumulation (retention) of metal ions in the membrane is also confirmed by the values of percentage extraction (a) and recovery factor (b) of $\mathrm{Zn}$ (II), $\mathrm{Fe}$ (II) and $\mathrm{Fe}(\mathrm{III})$ and shown in Fig. 6.

Fig. 6. The comparison of the values of extraction efficiency (a) and recovery factor (b) of $\mathrm{Zn}$ (II) (匹), Fe(II) (I/I) and Fe(III) (口) through PIMs and SLMs.

The transport of $\mathrm{Zn}(\mathrm{II})$ and $\mathrm{Fe}(\mathrm{III})$ across PIMs and SLMs is effective which is confirmed by the values of extraction efficiency to the membrane and recovery factor ranging from 60 to almost 100\% (Fig. 6). The highest Zn(II) extraction efficiency is obtained for SLM containing Cyphos IL 167 (extraction efficiency almost 100\%). However, the values of RF do not exceed 85\%. On 
the contrary, $\mathrm{Fe}$ (II) transport generally is not effective; the values of recovery factor are smaller than $10 \%$ but for SLMs the extracted Fe(II) is transferred to the receiving phase, while for PIMs accumulation in the membranes occurs. The obtained results show that the metal ions are successfully transported from the feed phase to the membrane, but their transport to the receiving phase is less effective, especially across PIMs. It may be explained by slower decomposition at the interface of the membrane-receiving phase compared with the rate of complex formation at the feed-membrane interface and also by restricted mobility of the carrier resulting from the way of PIM formation (as it was mentioned above).

As a consequence of existence of different species of $\mathrm{Zn}$ (II), $\mathrm{Fe}$ (III) and $\mathrm{Fe}$ (II) in chloride solutions and basing on the transport considerations given above it is assumed that these metal ions can be separated from one another according to eqs. 7-11. Selectivity of metal ion separation with PIMs and SLMs was calculated according to the following relationship:

$$
S_{M 1 / M 2}=\frac{c_{M 1, R}}{c_{M 1,0}} \cdot \frac{c_{M 2,0}}{c_{M 2, R}}
$$

where indices $M 1$ and $M 2$ denote each separated metal, $c_{0}(\mathrm{M})$ and $c_{R}(\mathrm{M})$ are the concentrations of metal ions in the feed phase at initial time and in the receiving phase after selected time. Values of separation coefficients are presented in Table 3.

Table 3. Separation of Zn(II), Fe(II) and Fe(III) with PIMs and SLMs

In PIM system the best separation of Zn(II) and Fe(III) from Fe(II) was obtained with Cyphos IL 167 as metal ion carrier - the values were infinitely high because no transport of $\mathrm{Fe}$ (II) to the 
receiving phase occurred. In the case of SLMs separation of $\mathrm{Zn}(\mathrm{II})$ from $\mathrm{Fe}(\mathrm{II})$ with both chloride ILs was very high $\left(\mathrm{S}_{\mathrm{Zn}(\mathrm{II}) / \mathrm{Fe}(\mathrm{II})}\right.$ near 10). Also, an effective separation of Fe(III) from $\mathrm{Fe}(\mathrm{II})$ with each of the studied ILs was obtained. On the contrary, $\mathrm{S}_{\mathrm{Zn}(\mathrm{II} / \mathrm{Fe}(\mathrm{III})}$ values smaller than 1 meant that $\mathrm{Zn}$ (II) could not be separated from Fe(III) both in SLM and PIM systems. The separation effectiveness with the phosphonium carriers in PIMs increased in the following order: Cyphos IL 104 < Cyphos IL 101 < Cyphos IL 167. Compared with PIM system, separation of $\mathrm{Zn}$ (II) over Fe(III) with SLM is poorer regardless of the carrier used and separation coefficients are lower than for PIMs. Transport of $\mathrm{Zn}$ (II) and Fe(III) chlorocomplexes is competitive and the only solution to separate $\mathrm{Zn}$ (II) from $\mathrm{Fe}(\mathrm{III})$ is to reduce the latter to $\mathrm{Fe}(\mathrm{II})$ prior to separation process.

\section{Stability of PIMs and SLMs}

Stability of the membranes and possibility to reuse them for further processes is an important issue. Stability of the membranes containing Cyphos IL 101 in three cycles, each 48-hour-long consisting of the membrane process and washing with water, is shown in Fig. 7. Cyphos IL 101 was chosen for stability studies, though in some cases Cyphos IL 167 performed very good separation of Zn(II) and Fe(III) from Fe(II) but membranes with Cyphos IL 101 more effectively transport $\mathrm{Zn}$ (II) to the receiving phase than other carriers studied. Moreover, PIMs containing Cyphos IL 167 were more brittle and have less mechanical strength than Cyphos IL 101 membranes.

Fig. 7. Stability of a) PIM and b) SLM containing Cyphos IL 101 on Zn(II) transport; extraction efficiency $(\boldsymbol{\bullet})$, recovery factor $(\square)$. 
It is obvious that in the process conditions investigated for these two systems SLM with Cyphos IL 101 carrier shows very good stability of $\mathrm{Zn}$ (II) in relation to PIM system with the same type of carrier (Fig. 7). Zn(II) extraction and recovery across SLM does not change in three cycles of use of the same membrane, whereas for PIM significant decrease (of about 40\%) in transport efficiency is noted. The most probable reason for the instability of the PIM studied is the loss of carrier.

Stability, called also reusability, of PIMs with phosphonium ILs was studied by Kogelnig et al. (19), Pospiech (24) and Guo et al. (40). Their studies provided various results due to different compositions of the PIMs investigated (Table 4), however, a decrease in permeability or weight of membranes was always observed.

PIMs with some types of carriers appeared to be more stable, e.g. Kebiche-Senhadji et al. (14) reported almost no change in Cd(II) flux across CTA-based PIMs with Aliquat 336 or D2EHPA as carriers for 96 hours (12 cycles, $8 \mathrm{~h}$ each cycle) and $\mathrm{Cr}(\mathrm{VI})$ and $\mathrm{Cr}(\mathrm{III})$ flux remained almost unchanged (5\% decrease) for 60 days (15). Also, PIMs containing Kelex 100 as $\mathrm{Au}(\mathrm{III})$ carrier were stable for 15 cycles $(6 \mathrm{~h}$ each), further decrease in permeability was attributed to the dissolution of the components of the organic phase in the aqueous media (16).

Table 4. Composition of different PIMs and SLMs and their stability results.

Generally some authors indicated that SLMs were less stable than PIMs. However, the metal ion flux, permeability or recovery factor decreased in each consecutive cycle in both 
membrane systems. Ulewicz and Radzyminska-Lenarcik (10) reported rather low decrease in $\mathrm{Zn}$ (II) transfer flux (less than 7.5\%) for PIM containing 1-decyl-4-methylimidazol as a carrier after 5 cycles. While the decrease in $\mathrm{Zn}(\mathrm{II})$ transfer across SLM was more significant, i.e. $35 \%$ after 5 cycles.

\section{conclusions}

The obtained results show that the transport of the metal ions through SLMs and PIMs is comparable and indicate that phosphonium ionic liquids are mobile carriers to transfer $\mathrm{Zn}$ (II) and $\mathrm{Fe}$ (III) from the feed to the receiving phase. Generally, transport of metal ions across SLMs is faster than across PIMs. For SLM and PIM containing Cyphos IL 101 and Cyphos IL 167 as metal ion carrier over $80 \%$ of the initial amount of $\mathrm{Zn}(\mathrm{II})$ and $\mathrm{Fe}(\mathrm{III})$ is extracted, while in the case of Fe(II) this value is less than 40\%. Cyphos IL 104 extracts Zn(II) and Fe(III) as good as IL 101 and IL 167 only across PIMs. It seems that the structure of the carrier used affects the metal transport efficiency. The obtained results showed that metal ion-Cyphos IL 101 and Cyphos IL 167 complexes may easier decompose at the interface of the membrane-receiving phase, thus, leading to higher values of transport parameters than for membranes containing Cyphos IL 104. The initial transport of the three metal ions is small, however, finally values of extraction efficiency and recovery factor are comparable both for PIMs and SLMs. On one hand, separation of $\mathrm{Zn}$ (II) and $\mathrm{Fe}$ (III) from Fe(II) is more effective in PIM systems. The separation effectiveness of $\mathrm{Zn}$ (II) with the phosphonium carriers in PIMs increases in the following order: Cyphos IL 104 $<$ Cyphos IL 101 < Cyphos IL 167. On the other hand, SLMs work more stably in some consecutive steps of extraction-washing cycles. This means that depending on the needs that 
should be realized, i.e. separation of specific metal ions or processing in many cycles, one may choose PIMs or SLMs, respectively.

\section{ACKNOWLEDGMENT}

This work was supported by the 03/32/DS-PB/0601 Polish grant and CTM2014-52770R grant from the Spanish Ministry of Education, Culture and Sport.

references

Nghiem, L.D.; Mornane, P.; Potter, I.D.; Perera, J.M.; Catrall, R.W.; Kolev, S.D. (2006) Extraction and transport of metal ions and small organic compounds using polymer inclusion membranes (PIMs). J. Membr. Sci., 281: 7.

Iněs, M.; Almeida, G.S.; Catrall, R.W.; Kolev, S.D. (2012) Recent trends in extraction and transport of metal ion using polymer inclusion membrane (PIMs). J. Membr. Sci., 415: 9.

Kislik, V.S. (Ed.) (2010) Liquid membranes. Principles and Applications in Chemical Separations and Wastewater Treatment, 1stEd; Elsevier: Amsterdam, the Netherlands.

Pospiech, B.; Kujawski, W. (2015) Ionic liquids as selective extractants and ion carriers of heavy metal ions from aqueous solutions utilized in extraction and membrane separation. Rev. Chem. Eng., 31 (2): 179.

Kim, J.S.; Kim, S.K.; Ko, J.; Kim, E.T.; Yu, S.H.; Cho, M.; Kwon, H.; Lee, S.G. (2000) Selective transport of cesium ion in polymeric CTA membrane containing calixcrown ethers. Talanta, 52: 1143. 
Fontàs, C.; Tayeb, R.; Tingry, S,; Hidalgo, M.; Seta, P. (2005) Transport of platinum(IV) through supported liquid membrane (SLM) and polymeric plasticized membrane (PPM). $J$. Membr. Sci., 263: 96.

Ugur, A.; Sener, I.; Hol, A.; Alpoguz, H.K.; Elçi, L. (2014) Facilitated transport of Zn(II) and $\mathrm{Cd}(\mathrm{II})$ ions through polymer inclusion membranes immobilized with a calix[4] resorcinarene derivative. J. Macromol. Sci., Pure Appl. Chem., 51 (8): 611.

Baczynska, M.; Regel-Rosocka, M.; Wiśniewski, M. (2013) Use of polymer inclusion membranes in processes for metal ion transport, Przem. Chem., 92 (6): 928.

Ugur, A.; Sener, I. (2015) The removal of Zn(II) through calix[4]resorcinarene derivative based polymer inclusion membrane from aqueous solution. J. Macromol. Sci., Pure Appl. Chem., 52: 801.

Ulewicz, M.; Radzymińska-Lenarcik, E. (2014) Application of polymer and supported membranes with 1-decyl-4-methylimidazole for pertraction of transition metal ions. Sep. Sci. Technol., 49: 1713.

Castillo, J.; Coll, M. T.; Fortuny, A.; Navarro-Donoso, P.; Sepúlveda, R.; Sastre, A. M. (2014) $\mathrm{Cu}(\mathrm{II})$ extraction using quaternary ammonium and quaternary phosphonium based ionic liquid. Hydrometallurgy, 141: 89.

Paugam, M. F.; Buffle, J. (1998) Comparison of carrier-faciliteted copper (II) ion transport mechanism in a supported liquid membrane and in a plasticized cellulose triacetate membrane. $J$. Membr. Sci., 147: 207. 
Fontàs, C.; Tayeb, R.; Dhahbi, M.; Gaudichet, E.; Thominette, F.; Roy, P.; Steenkeste, K.; Fontaine-Aupart, M. P.; Tingry, S.; Tronel-Peyroz, E.; Seta, P. (2007) Polymer inclusion membranes: The concept of fixed sites membrane revised. J. Membr. Sci., 290: 62.

Kebiche-Senhadji, O.; Mansouri, L.; Tingry, S.; Seta, P.; Benamor, M. (2008) Facililated Cd(II) transport across CTA polymer inclusion membrane using anion (Aliquat 336) and cation (D2EHPA) metal carriers. J. Membr. Sci., 310: 438.

Konczyk, J.; Kozłowski, C.; Walkowiak, W. (2010) Removal of chromium(III) from acidic aqueous solution by polymer inclusion membranes with D2EHPA and Aliquat 336. Desalination, 263: 211.

Rodriguez de San Miguel, E.; Garduno-Garcia, A.V.; Aguilar, J.C.; de Gyves, J. (2007) Gold(III) transport through polymer inclusion membranes: efficiency factors and pertraction mechanism using Kelex 100 as carrier.Ind. Eng. Chem. Res., 46 (9): 2861.

Arslan, G.; Tor, A.; Muslu, H.; Ozmen, M.; Akin, I.; Cengeloglu, Y.; Ersoz, M. (2009) Facilitated transport of $\mathrm{Cr}(\mathrm{VI})$ through a novel activated composite membrane containing Cyanex 923 as carrier. J. Membr. Sci., 337: 224.

Fortuny, A.; Coll, M. T.; Sastre, A. M. (2012) Use of methyltrioctyl/decylammonium bis 2,4,4(trimethylpentyl)phosphinate ionic liquid (ALiCY) on the boron extraction in chloride media. Sep. Purif. Technol., 97: 137.

Kogelnig, D.; Regelsberger, A.; Stojanovic, A.; Jirsa, F.; Krachler, R.; Keppler B.K. (2011) A polymer inclusion membrane based on the ionic liquid trihexyl(tetradecyl)phosphonium chloride 
and PVC for solid-liquid extraction of Zn(II) from hydrochloric acid solution. Monatsh. Chem., 142: 769 .

Baczynska, M.; Regel-Rosocka, M. (2013) Phosphonium ionic liquids as carriers of metal ions. Przem. Chem., 92 (9): 1574.

Baczynska, M.; Regel-Rosocka, M.; Nowicki, M.; Wisniewski, M. (2015) Effect of the structure of polymer inclusion membranes on $\mathrm{Zn}$ (II) transport from chloride aqueous solutions. J. Appl. Polym. Sci., 132 (30): 42319.

Baczynska, M.; Rzelewska, M.; Regel-Rosocka, M.; Wisniewski, M. (2016) Transport of iron ions from chloride solutions using cellulose triacetate matrix inclusion membranes with an ionic liquid carrier. Chem. Pap., 70 (2): 172.

Regel-Rosocka, M.; Nowak, Ł.; Wiśniewski, M. (2012) Removal of zinc(II) and iron from chloride solutions with phosphonium ionic liquids. Sep. Purif. Technol., 97: 158.

Pospiech, B. (2015) Studies in extraction and permeation of cadmium(II) using Cyphos IL 104 as selective extractant and ion carrier. Hydrometallurgy, 154: 88.

Fortuny, A.; Coll, M. T.; Sastre, A. M. (2014) Ionic liquids as a carrier for chloride reduction from brackish water using hollow fiber renewal liquid membrane. Desalination, 343: 54.

Gherassim, C.V.; Bourceanu, G.; Olariu, R.I; Arsene, C. (2011) A novel polymer inclusion membrane applied in chromium (VI) separation from aqueous solutions. J. Hazard. Mater., 197: 244. 
Cho, Y.; Xu, C.; Catrall, R.W.; Kolev, S.D. (2011) A polymer inclusion membrane for extracting thiocyanate from weakly alkaline solutions. J. Membr. Sci., 376: 85.

Kozłowska, J.; Kozłowski, C.A.; Kozioł, J.J. (2007) Transport of Zn(II), Cd(II) and Pb(II) across CTA plasticizer membranes containing organophosphorous acids as an ion carriers. Sep. Purif. Technol., 57: 430.

Regel-Rosocka, M.; Szymanowski, J. (2005) Iron(III) transfer to the organic phase during zinc(II) extraction from spent pickling solutions with tributyl phosphate. Solvent Extr. Ion Exch., 23: 411.

Regel-Rosocka, M. (2010) A review on methods of regeneration of spent pickling solutions from steel processing. J. Hazard. Mater., 177 (1-3): 57.

Carrillo-Abad, J.; Garcia-Gabaldon, M.; Ortiz-Gandara, I.; Bringas, E.; Urtiaga, A.M.; Ortiz, I.; Perez-Herranz, V. (2015) Selective recovery of zinc from spent pickling baths by the combination of membrane-based solvent extraction and electrowinning technologies. Sep. Sci. Technol., 151: 232.

Regel-Rosocka, M.; Wisniewski, M. (2011) Selective removal of zinc(II) from spent pickling solution in the presence of iron ions with phosphonium ionic liquid Cyphos IL 101. Hydrometallurgy, 110: 85.

Cook, S.J.; Perera, J.M.; Stevens, G.W.; Kentish, S.E. (2011) The screening of extractants for the separation of Zn(II) from Australian hot-dip galvanizing effluent. Sep. Sci. Technol., 46: 2066. 
Laso, J.; García, V.; Bringas, E.; Urtiaga, A.M.; Ortiz, I. (2015) Selective recovery of zinc over iron from spent pickling wastes by different membrane-based solvent extraction process configurations. Ind. Eng. Chem. Res., 54: 3218.

Lum, K.H.; Cook, S.J.; Stevens, G.W.; Perera, J.M.; Kentish, S.E. (2014) Zinc chloride and hydrochloric acid coextraction from galvanizing pickling waste in the presence of iron(II). Results with hollow fiber membrane contactors. Ind. Eng. Chem. Res., 53: 4453.

Machado, R.M.; Gameiro, M.L.F.; Krupa, M.; Rodrigues, J.M.A.; Ismael, M.R.C.; Reisa M.T.A.; Carvalho, J.M.R. (2015) Selective separation and recovery of zinc and lead from galvanizing industrial effluents by anion exchange. Sep. Sci. Technol., 50: 2726.

Cytec Industries (2008). Cyanex 272 extractant. March 16, 2016, from http://www.cytec.com/sites/default /files/datasheets/CYANEX272Brochure.pdf.

Resina, M.; Fontas, C.; Palet, C.; Munoz, M. (2008) Comparative study of hybrid and activated composite membranes containing Aliquat 336 for the transport of Pt(IV). J. Membr. Sci., 311: 235.

Aguilar, J.C.; Sanchez-Castellanos, M.; Rodriguez de San Miguel, E.; de Gyves, J. (2001) Cd(II) and $\mathrm{Pb}(\mathrm{II})$ extraction and transport modeling in SLM and PIM systems using Kelex 100 as carrier. J. Membr. Sci., 190: 107.

Guo, L.; Liu, Y.; Zhang, C.; Chen, J. (2011) Preparation of PVDF-based polymer inclusion membrane using ionic liquid plasticizer and Cyphos IL 104 carrier for $\mathrm{Cr}(\mathrm{VI})$ transport. $J$. Membr. Sci., 372: 314. 
Fig. 1. Structures of the phosphonium ionic liquids used as PIM carriers.

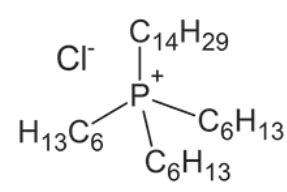

Cyphos IL 101,

Trihexyl(tetradecyl)phosphonium chloride

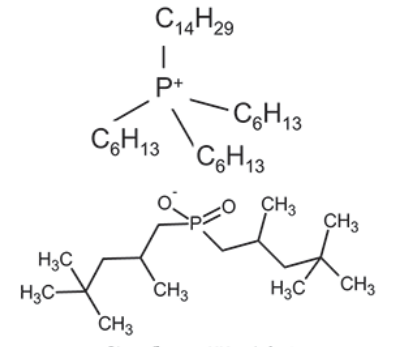

Cyphos IL 104,

Trihexyl(tetradecyl)phosphonium bis(2,4,4-trimethylpentyl)phosphinate<smiles>CCCCCCC</smiles>

Cyphos IL 167, Tributyl(tetradecyl)phosphonium chloride

Fig. 2. Schematic diagram of PIM system ( 1 - feed phase container, 2 - receiving phase container, 3 - peristaltic pump, 4 - membrane module - sandwich type).

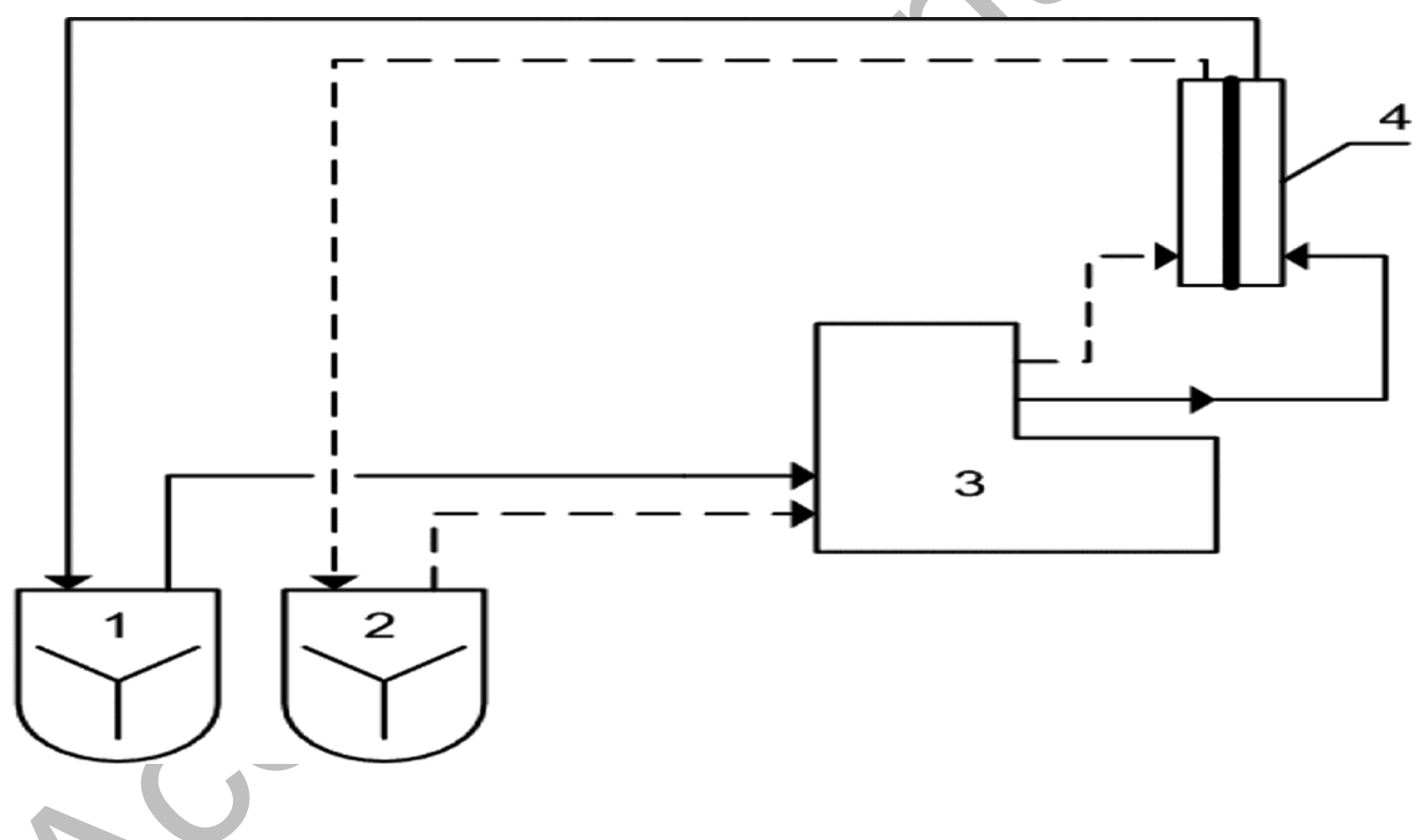

Fig. 3. Scheme of SLM system. 




Fig. 4. Changes in concentration of $(\boldsymbol{\bullet}) \mathrm{Zn}(\mathrm{II}),(\bullet) \mathrm{Fe}(\mathrm{II}),(\boldsymbol{\Delta}) \mathrm{Fe}(\mathrm{III})$ ions over time in the feed and receiving phase through SLMs with Cyphos IL 101 as a carrier.
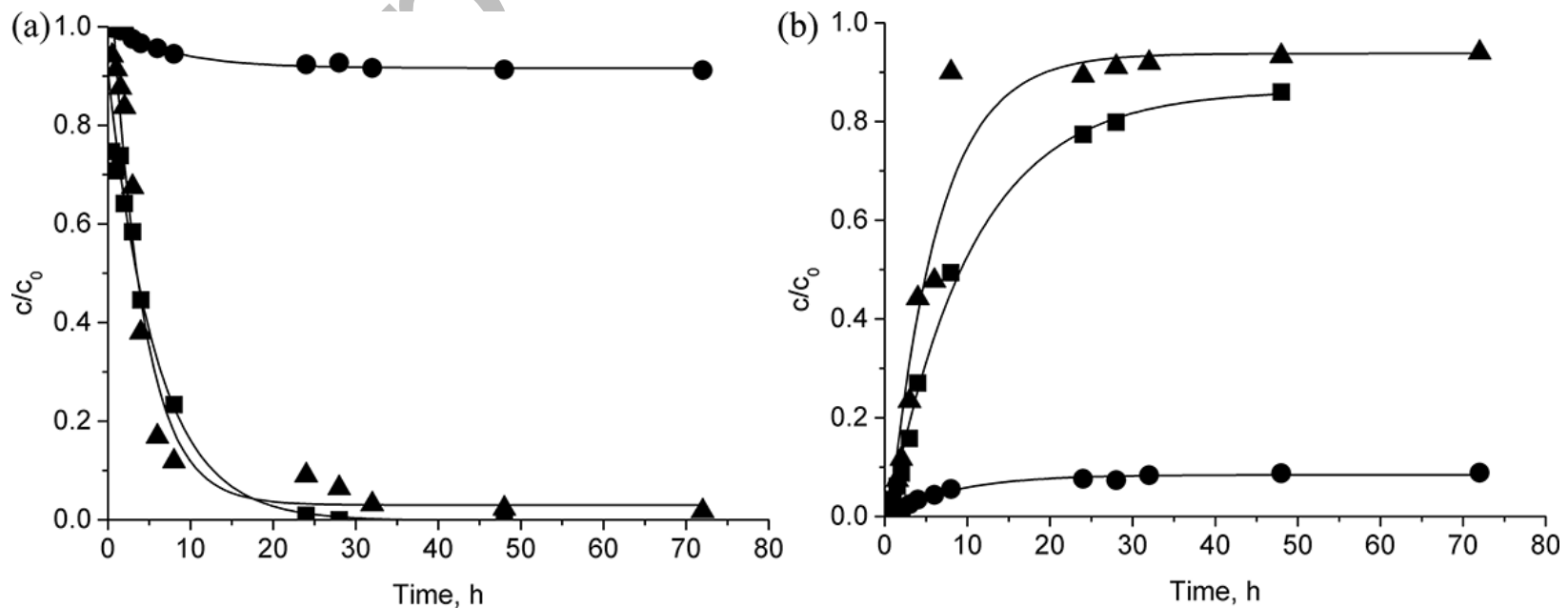
Fig. 5. Changes in concentration of $(\boldsymbol{\bullet}) \mathrm{Zn}(\mathrm{II}),(\bullet) \mathrm{Fe}(\mathrm{II}),(\boldsymbol{\Delta}) \mathrm{Fe}(\mathrm{III})$ ions over time in the feed and receiving phase through PIMs with Cyphos IL 101 as a carrier.
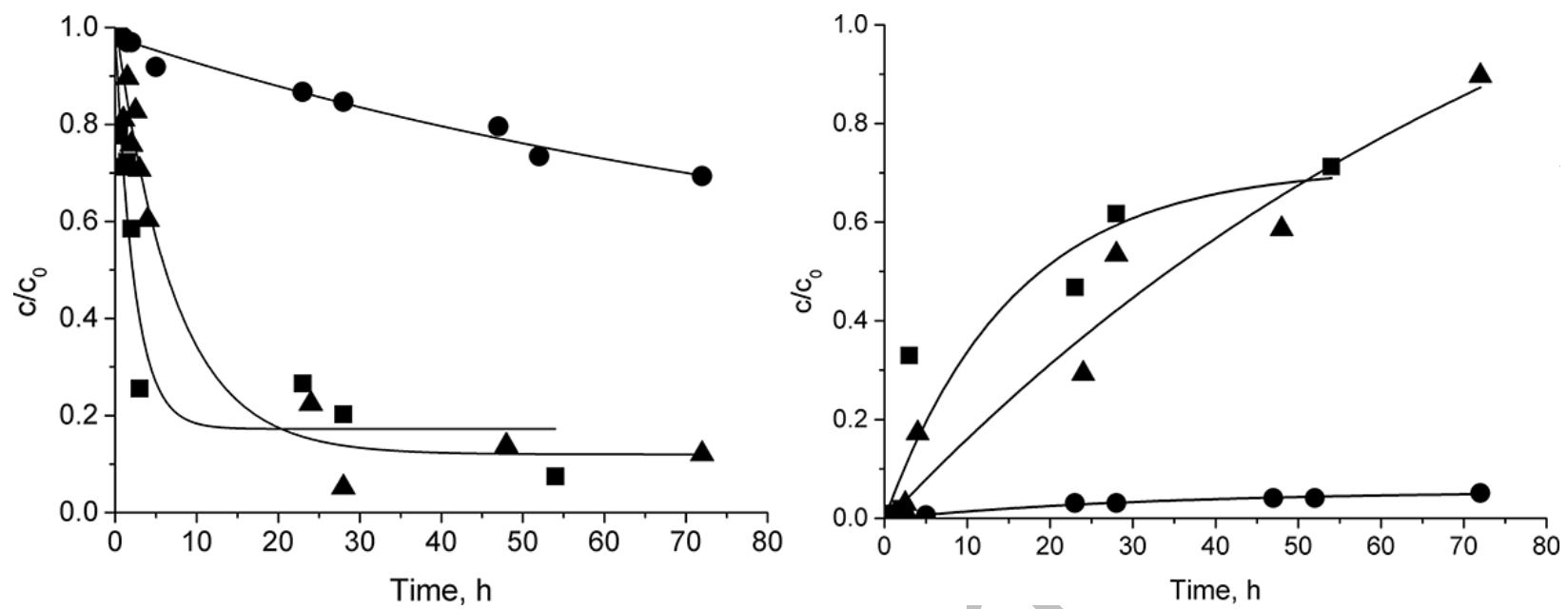

Fig. 6. The comparison of the values of extraction efficiency (a) and recovery factor (b) of $\mathrm{Zn}$ (II) (匹), $\mathrm{Fe}(\mathrm{II})(/ / /)$ and $\mathrm{Fe}(\mathrm{III})(\square)$ through PIMs and SLMs.
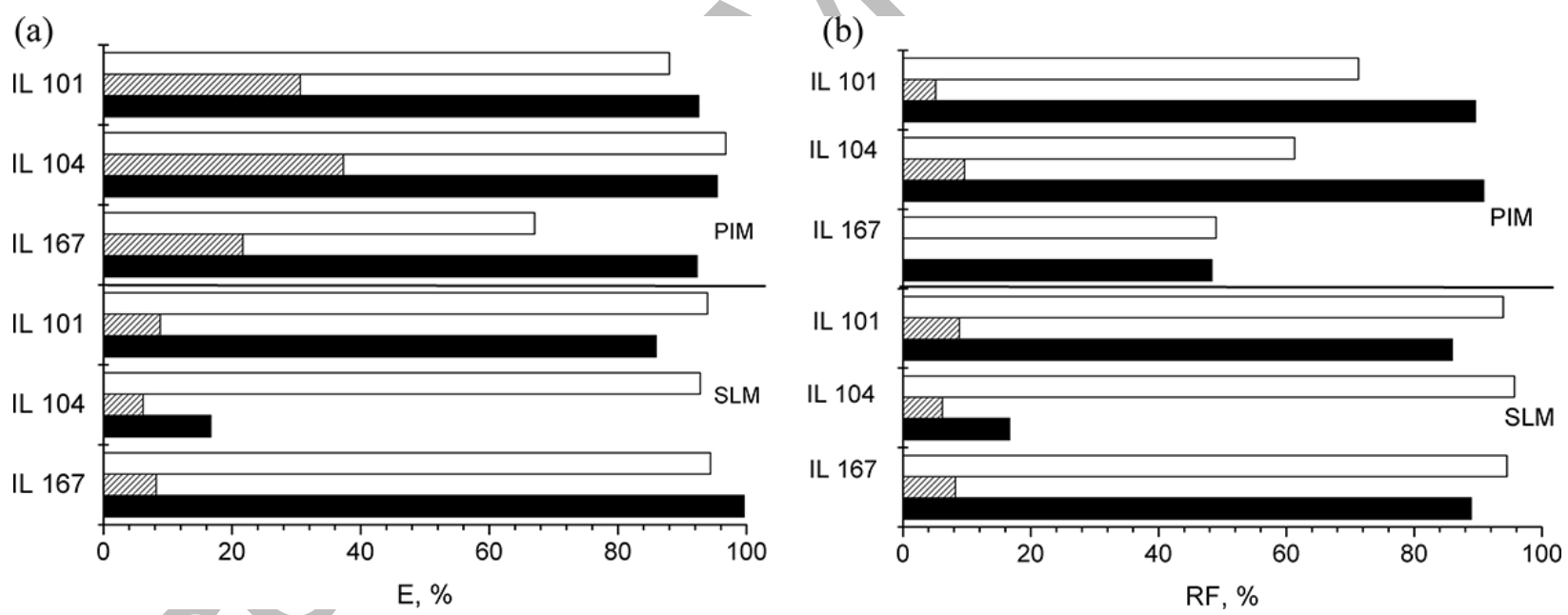

Fig. 7. Stability of a) PIM and b) SLM containing Cyphos IL 101 on Zn(II) transport; extraction efficiency ( $\mathbf{})$, recovery factor $(\square)$.

Supplementary Data 

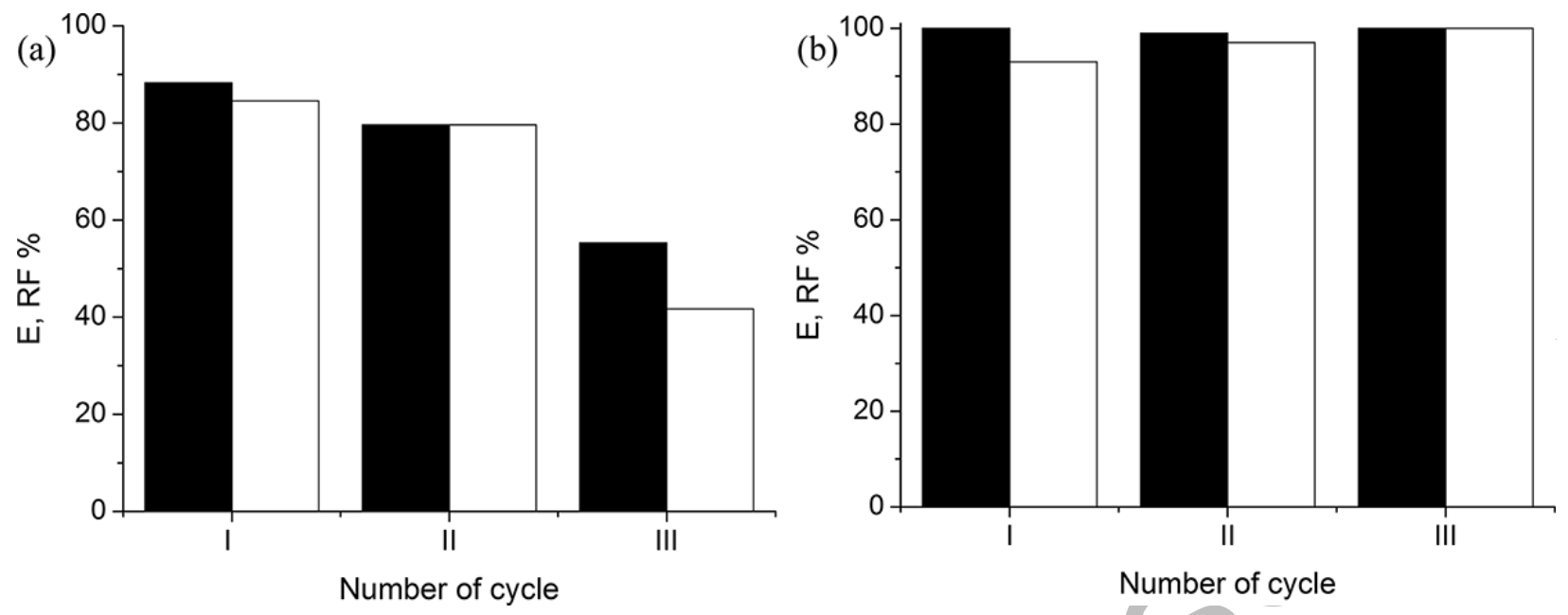

Table 1. Characteristic parameters of PIMs and SLMs applied for metal ion transport

\begin{tabular}{|l|l|l|}
\hline Parameter & PIM & SLM \\
\hline Polymer matrix/support & CTA & PVDF \\
\hline Diameter, cm & 7.0 & 4.5 \\
\hline Effective surface area, $\mathrm{cm}^{2}$ & 15.9 & 11.4 \\
\hline Thickness, $\mu \mathrm{m}$ & & \\
\hline Porosity, $\%$ & $\sim 30$ & 125 \\
\hline Pore size, $\mu \mathrm{m}$ & - & $75 \%$ \\
\hline
\end{tabular}




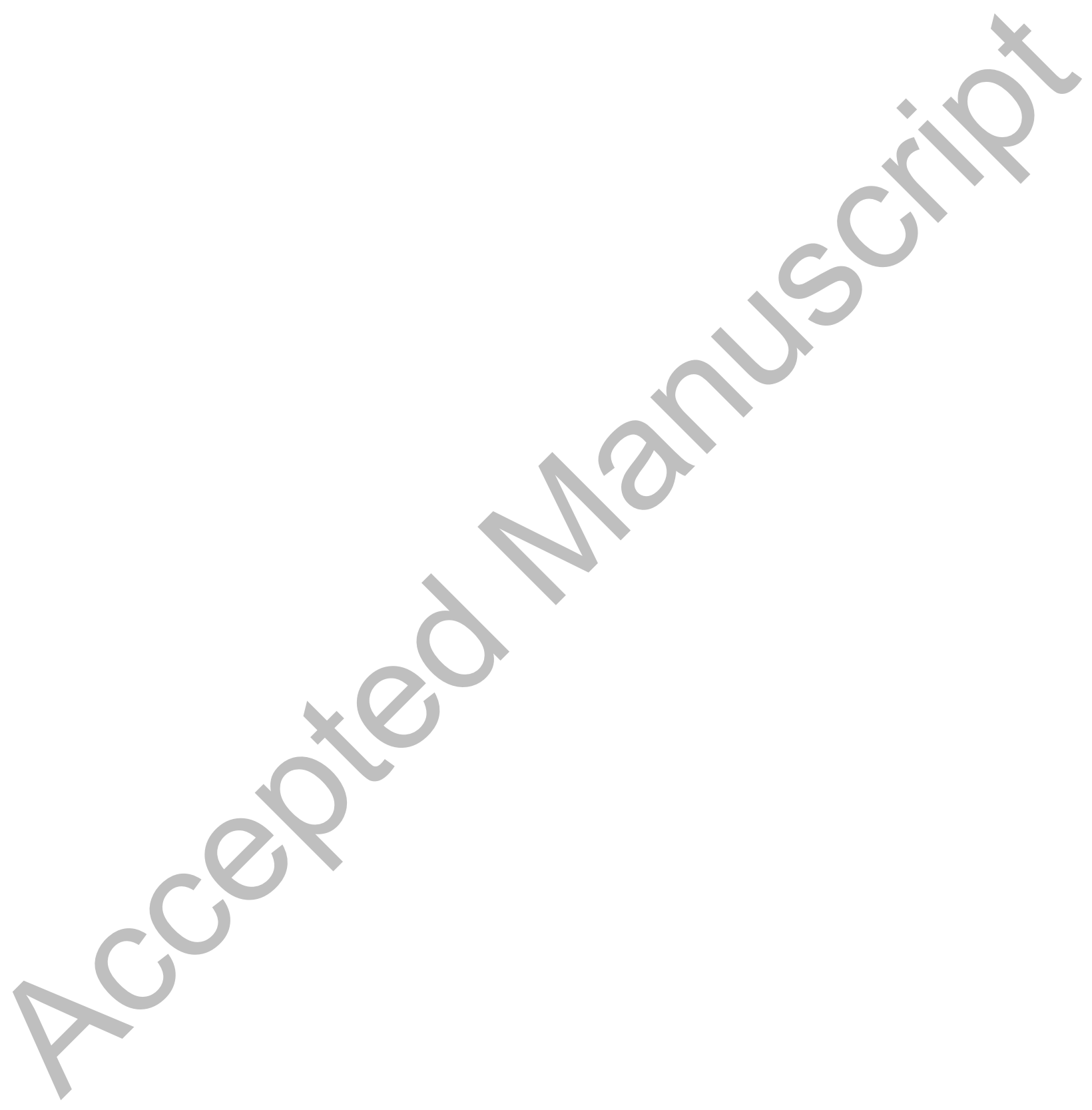


Table 2. The comparison of parameters characterizing transport of $\mathrm{Zn}$ (II), $\mathrm{Fe}$ (II) and $\mathrm{Fe}(\mathrm{III})$ through SLMs and PIMs.

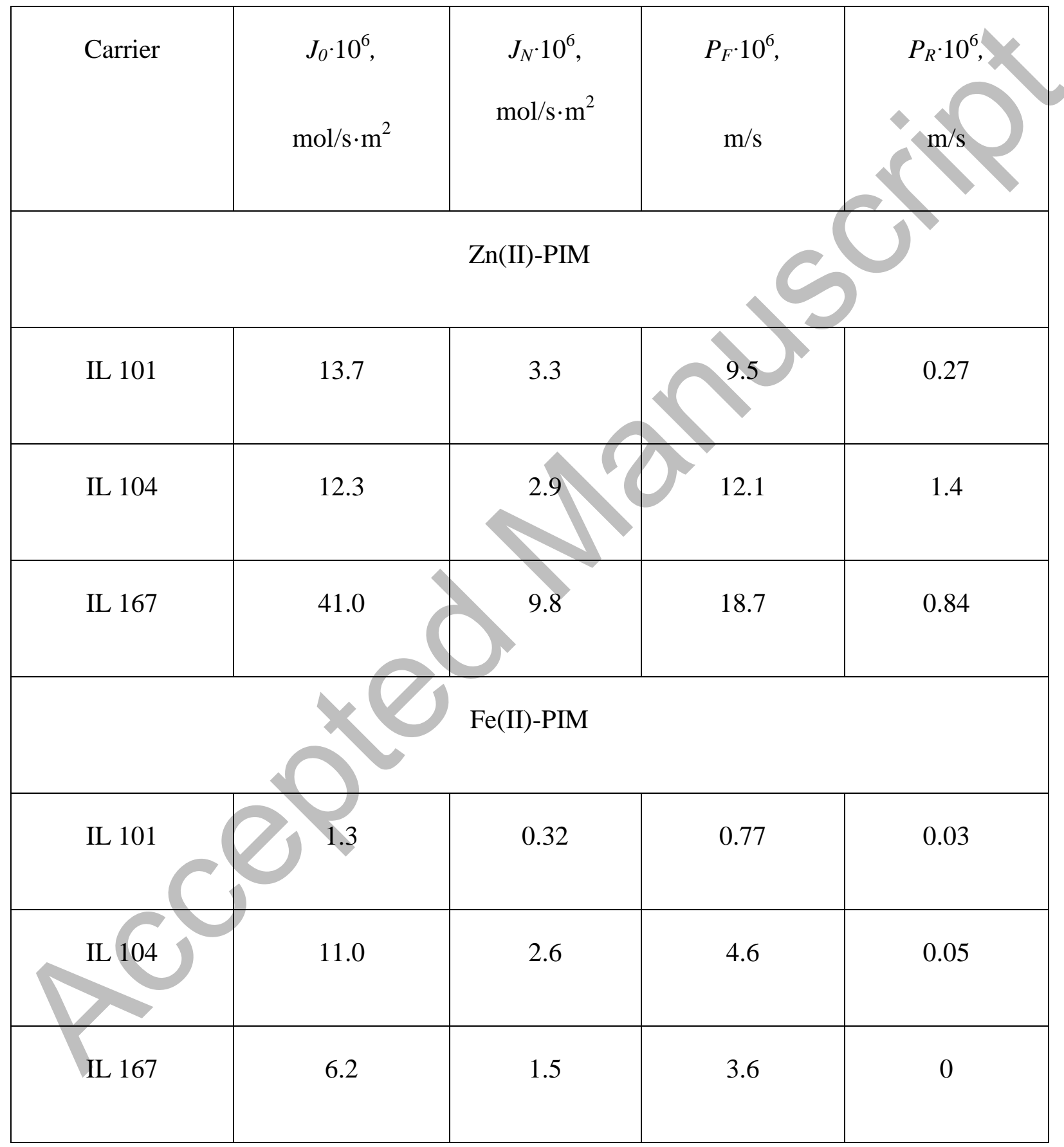




\begin{tabular}{|c|c|c|c|c|}
\hline \multicolumn{5}{|c|}{ Fe(III)-PIM } \\
\hline IL 101 & 6.5 & 1.6 & 6.3 & 1.3 \\
\hline IL 104 & 3.9 & 0.94 & 3.5 & 0.51 \\
\hline IL 167 & 3.8 & 0.91 & 2.4 & 0.3 \\
\hline IL 104 & & & & \\
\hline IL 101 & & & & \\
\hline & & & & \\
\hline
\end{tabular}




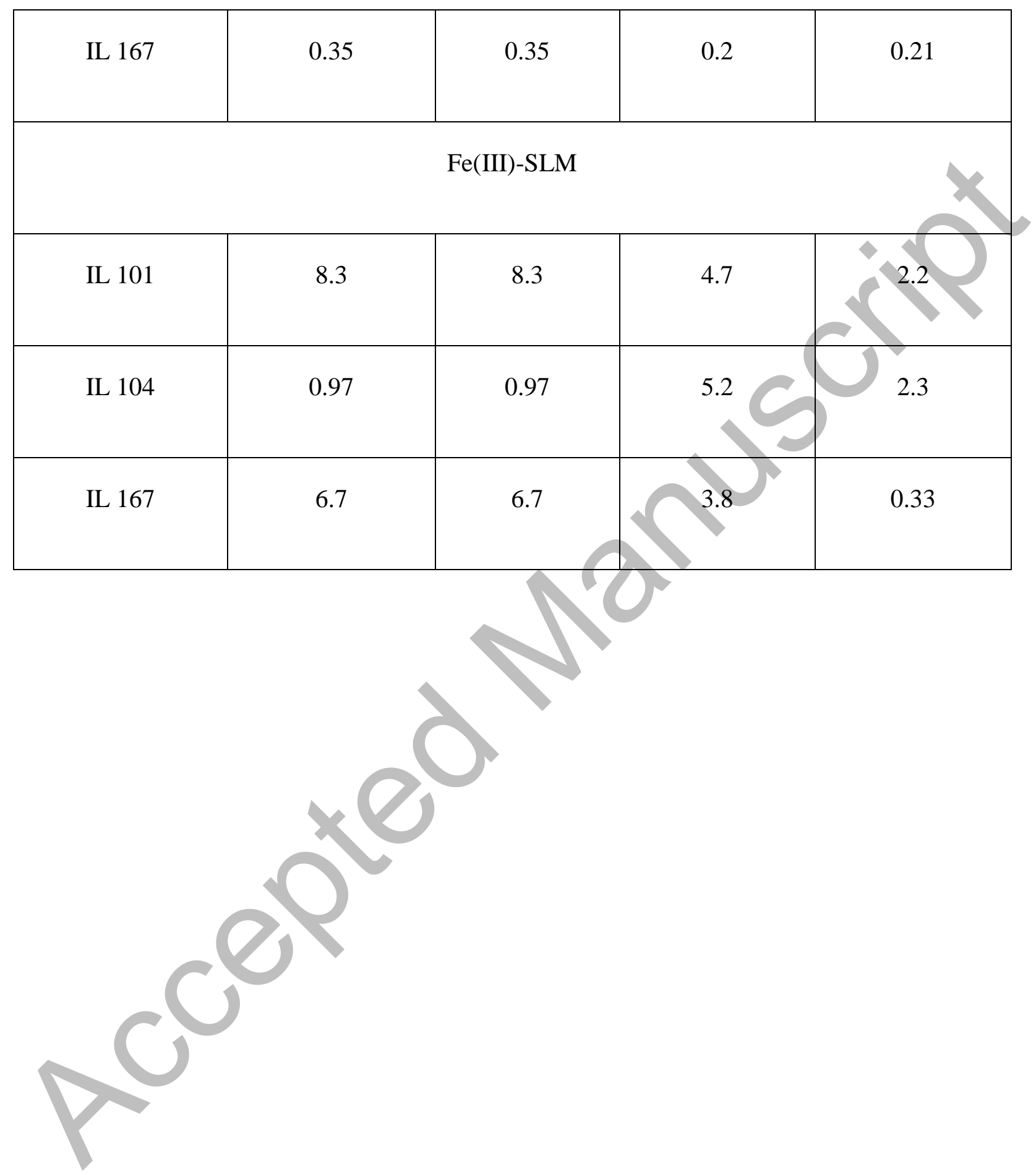


Table 3. Separation of Zn(II), Fe(II) and Fe(III) with PIMs and SLMs.

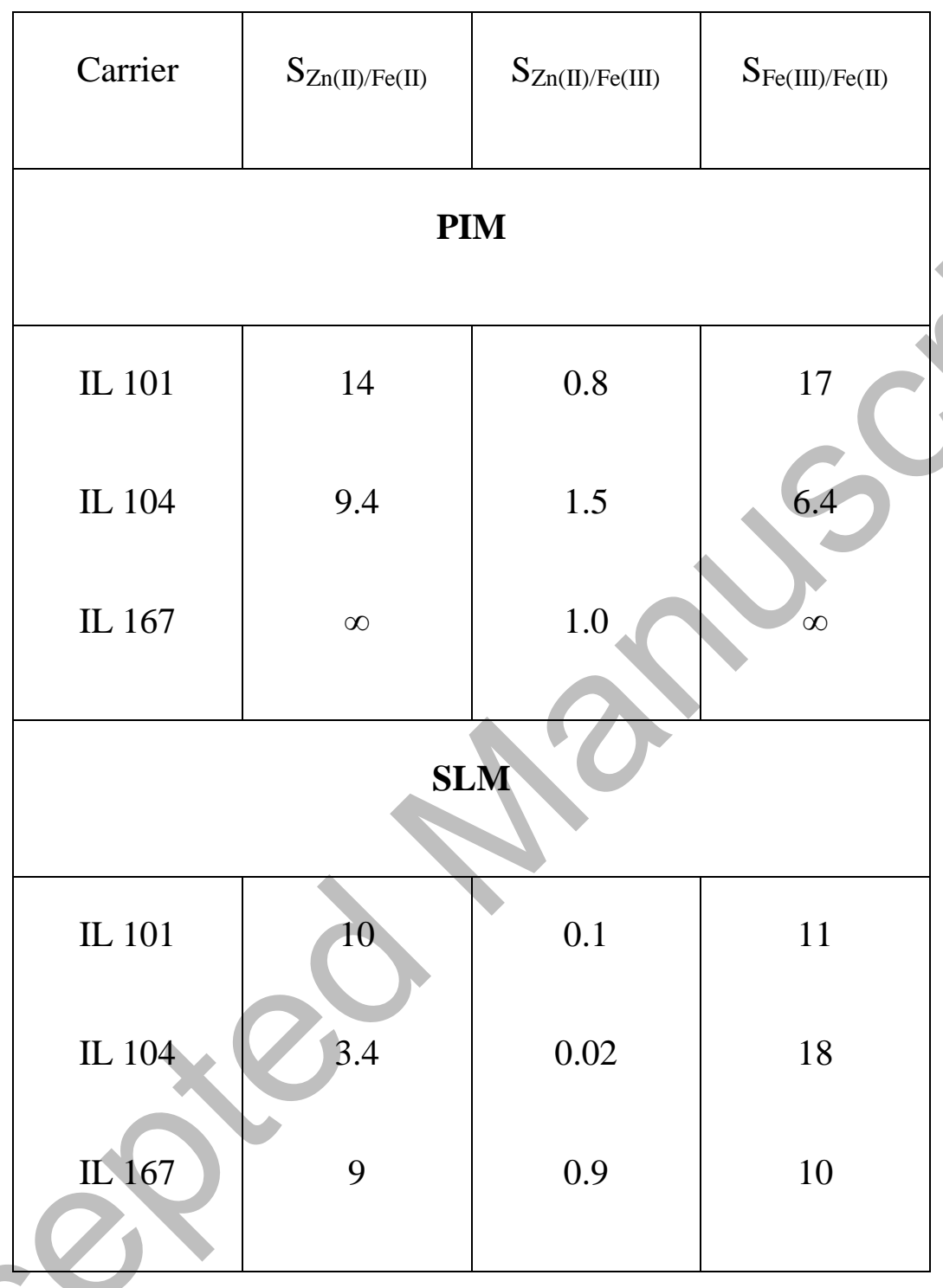


Table 4. Composition of different PIMs and SLMs and their stability results.

\begin{tabular}{|c|c|c|c|c|}
\hline \multicolumn{3}{|c|}{ Membrane composition } & \multirow[t]{2}{*}{ Stability } & \multirow[t]{2}{*}{ Ref. } \\
\hline Polymer & Plasticizer & Carrier & & \\
\hline CTA & NPOE & $\begin{array}{l}\text { Aliquat } 336 \text { or } \\
\text { D2EHPA }\end{array}$ & $\begin{array}{l}\text { Very stable for } 96 \text { hours ( } 12 \text { cycles, } 8 \text { h } \\
\text { each cycle) }\end{array}$ & (14) \\
\hline CTA & NPOE & $\begin{array}{l}\text { Aliquat } 336 \text { or } \\
\text { D2EHPA }\end{array}$ & $5 \%$ change in flux after 60 days & $(15)$ \\
\hline CTA & NPOE & Kelex 100 & Very stable for 90 hours $(15$ cycles, $6 \mathrm{~h}$ & (16) \\
\hline PVC & - & Cyphos IL 101 & $30 \%$ loss of weight after 26 days in water, & (19) \\
\hline PVDF & Imidazolium & Cyphos IL 104 & $\begin{array}{l}2 \% \text { loss of weight after } 26 \text { days in } 5 \mathrm{M} \\
\mathrm{HCl}\end{array}$ & $\begin{array}{l}(24) \\
(40)\end{array}$ \\
\hline & ILs & & $\begin{array}{l}18 \% \text { decrease in permeability after } \\
4 \text { cycles }(24 \mathrm{~h} \mathrm{each})\end{array}$ & \\
\hline & & & $30 \%$ decrease in permeablility after & \\
\hline
\end{tabular}




\begin{tabular}{|l|l|l|l|}
\hline & 9 cycles & \\
\hline
\end{tabular}

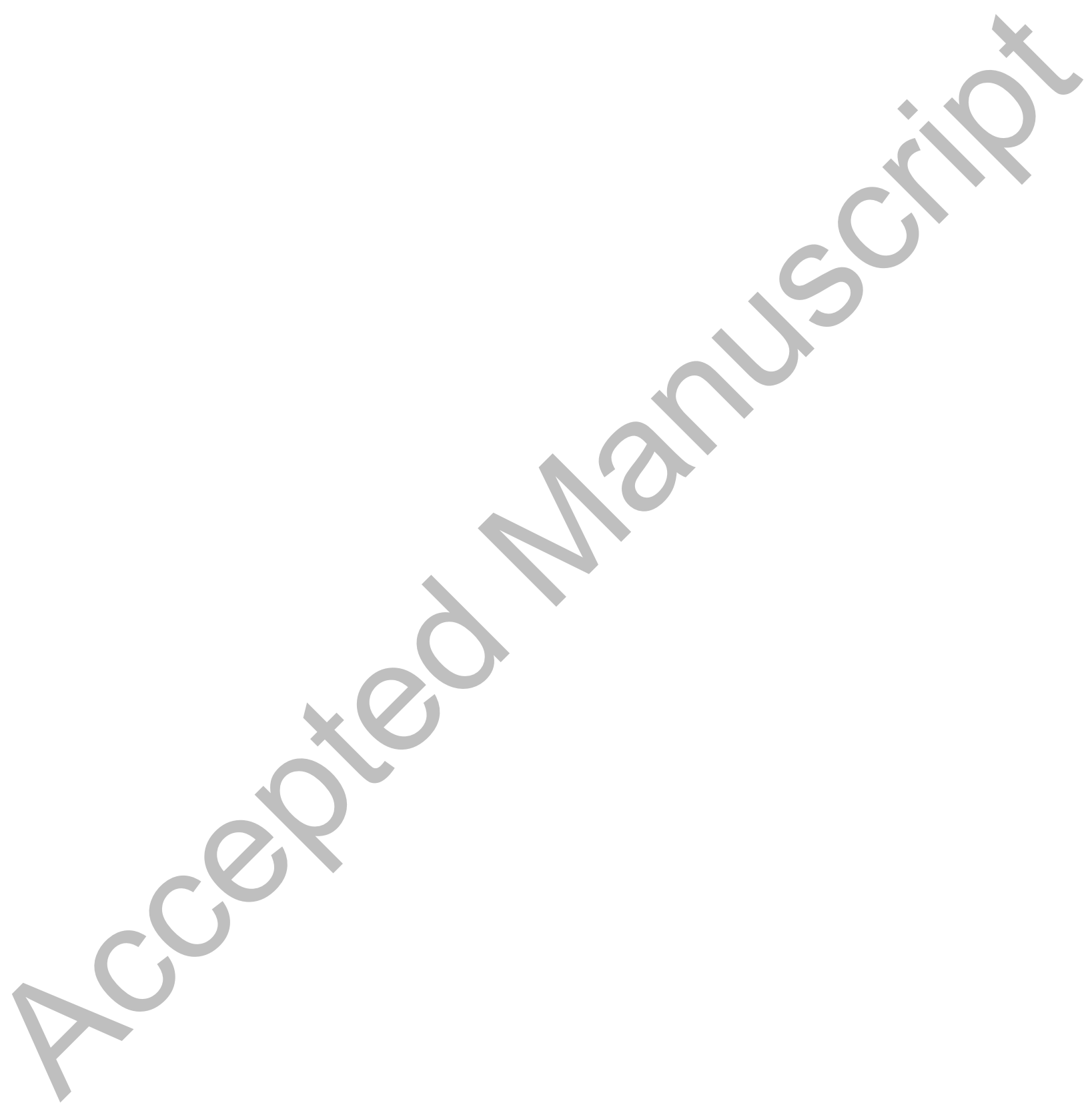




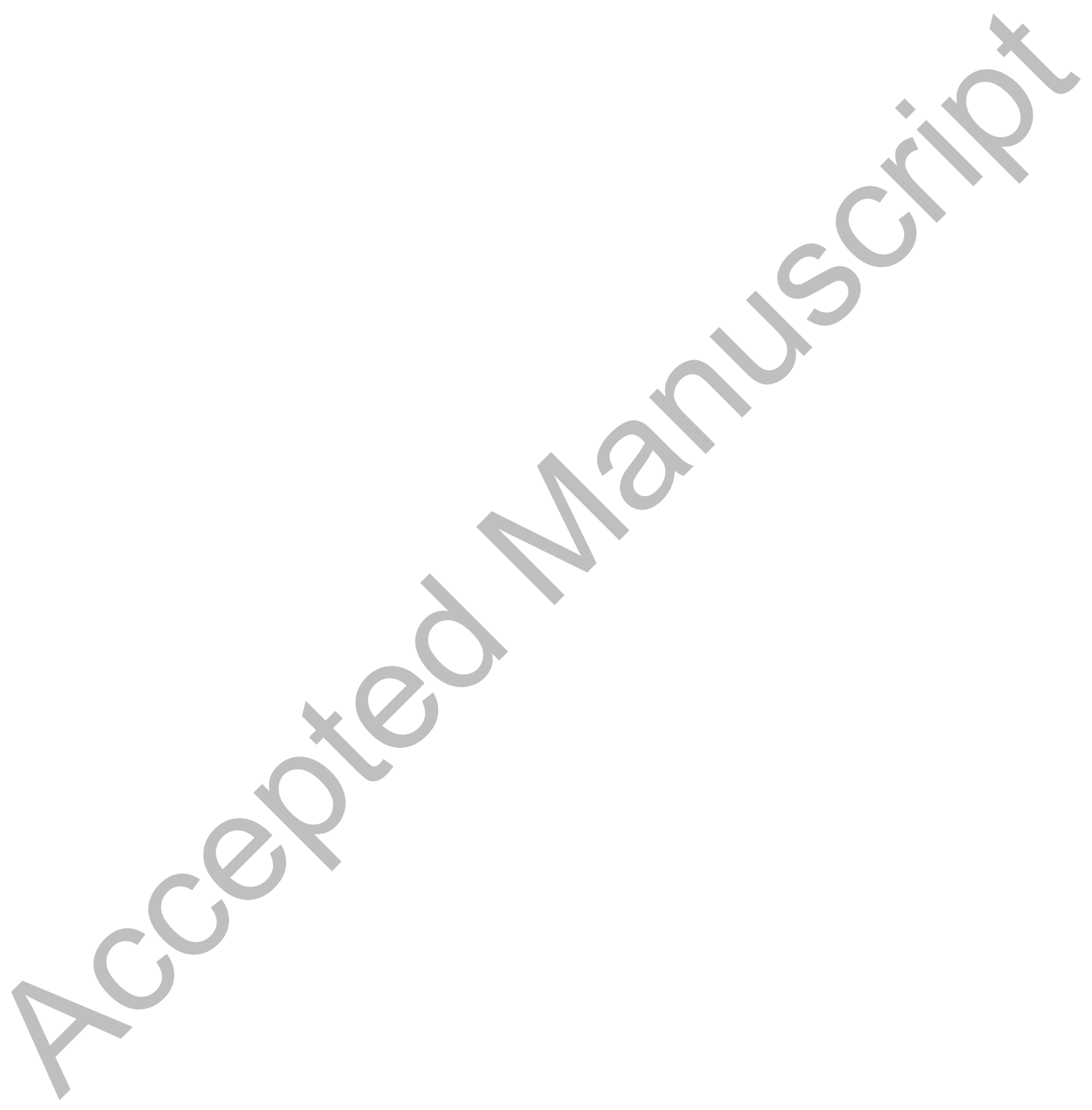

